\title{
Preparation of Microcapsules Containing Water and Effect of Water Content on Expansion Behavior
}

\author{
Yoshinari Taguchi, Natsukaze Saito, Kenji Oda, Masato Tanaka* \\ Graduate School of Science and Technology: Niigata University, Niigata-shi, Japan \\ Email: ^tanaka@eng.niigata-u.ac.jp
}

How to cite this paper: Taguchi, Y., Saito, N., Oda, K. and Tanaka, M. (2017) Preparation of Microcapsules Containing Water and Effect of Water Content on Expansion Behavior. Journal of Encapsulation and Adsorption Sciences, 7, 127-139. https://doi.org/10.4236/jeas.2017.74010

Received: September 29, 2017

Accepted: October 20, 2017

Published: October 26, 2017

Copyright $\odot 2017$ by authors and Scientific Research Publishing Inc. This work is licensed under the Creative Commons Attribution International License (CC BY 4.0).

http://creativecommons.org/licenses/by/4.0/

\begin{abstract}
The research work was conducted in order to establish the optimum conditions for preparing the expanded polystyrene beads without harmful substances and was aimed at the preparation of the microcapsules containing water and investigation of the effect of the water content on the expansion behavior of microcapsules. Microcapsules were prepared with the suspension polymerization method and the suspension polymerization in parallel with interfacial polycondensation method using the multiple emulsion (W/O)/W and adding a few additives. With increasing the crosslinking agent concentration in the suspension polymerization method, the water content increased from $\mathrm{R}$ $=5.8 \mathrm{wt} \%\left(\mathrm{C}_{\mathrm{T}}=0\right)$ to $\mathrm{R}=8.2 \mathrm{wt} \%\left(\mathrm{C}_{\mathrm{T}}=4 \mathrm{wt} \%\right)$ and then, decreased to $\mathrm{R}=7.5$ wt\% $\left(\mathrm{C}_{\mathrm{T}}=9.0 \mathrm{wt} \%\right)$, while the expansion ratio increased from $\mathrm{E}=1.01\left(\mathrm{C}_{\mathrm{T}}=\right.$ $0)$ to $\mathrm{E}=2.20\left(\mathrm{C}_{\mathrm{T}}=4 \mathrm{wt} \%\right)$ and then, decreased to $\mathrm{E}=1.01\left(\mathrm{C}_{\mathrm{T}}=7.0 \mathrm{wt} \%\right)$. With increasing the added amount of wax in the suspension polymerization method, the water content gradually increased from $\mathrm{R}=2.5 \mathrm{wt} \%$ to $\mathrm{R}=8.0$ $\mathrm{wt} \%$, while the expansion ratio increased from $\mathrm{E}=1.01$ to $\mathrm{E}=1.5$ and then, decreased. The water content and the expansion ratio could be increased by conducting suspension polymerization in parallel with interfacial polycondensation reaction from $\mathrm{R}=5.0 \mathrm{wt} \%$ to $\mathrm{R}=8.0 \mathrm{wt} \%$ and from $\mathrm{E}=1.01$ to $\mathrm{E}$ $=1.3$, respectively. The maximum expansion ratio of $\mathrm{E}=2.58$ in this work was obtained under the conditions of crosslinking agent concentration of $\mathrm{C}_{\mathrm{T}}=4.0$ wt \%, the added amount of wax of $3.0 \mathrm{~g}$, addition of Agarose and the expansion temperature of $\mathrm{T}=150^{\circ} \mathrm{C}$.
\end{abstract}

\section{Keywords}

Water Containing Microcapsules, Blowing Agent, Expanded Polystyrene, Suspension Polymerization, Interfacial Polycondensation 


\section{Introduction}

Microcapsules can contain as the core materials the various substances such as solid, liquid and gas and release optionally them [1] [2].

Also, microcapsules containing water among these core materials have been applied in a lot of fields such as pharmacy, adhesives, agriculture, cosmetics, food, textile, information recording materials and so on [1] [2], because water is the solvent being able to dissolve various inorganic and organic materials.

Until now, many works with respect to microencapsulation of water have been reported, in which water was microencapsulated using multiple emulsion like the (W/O)/W emulsion [3] [4] [5] [6].

In this preparation method, how to keep the (W/O) emulsion stably is extremely important in order to prepare the satisfactory microcapsules containing water.

Tanaka et al. have reported the results tried to form the stable (W/O) emulsion by increasing the viscosity of oil phase, changing the oil soluble surfactant species and their concentrations, conducting the interfacial polycondensation reaction between the inner water droplets and the oil phase and using the inverse Pickering emulsion [7] [8].

These works were aimed at decreasing the inner droplet diameter and preventing coalescence between the inner water droplets in an oil droplet.

Shiomori et al. have prepared the porous polystyrene beads applied to preparation of the microcapsules containing water with suspension polymerization by using the (W/O)/W emulsion [9] [10]. They have formed the stable (W/O)/W emulsion by selecting the oil and the water soluble surfactants.

Sekine et al. have formed the stable $(\mathrm{O} / \mathrm{W}) / \mathrm{O}$ emulsion using liquid paraffin as the inner oil phase and the outer oil phase, where hydrophobic nonionic surfactant and organophilic montmorillonite were added into the outer oil phase [4].

They have reported that the stable $(\mathrm{O} / \mathrm{W}) / \mathrm{O}$ emulsion could be formed mainly by increasing the viscosity of the outer oil phase in the $(\mathrm{O} / \mathrm{W}) / \mathrm{O}$ emulsion with lipophilic nonionic surfactant and organophilic montmorillonite.

The other works with regard to the formation of the stable (W/O)/W emulsion have investigated the effects of the optimum hydrophilic and lipophilic surfactant species and the physical properties of multiple emulsion [11] [12].

Also, Tanaka et al. have prepared the microcapsules containing water, in which the $(\mathrm{W} / \mathrm{O})$ emulsion was stabilized by adding $\mathrm{TiO}_{2}$ powder as a particulate stabilizer into the oil phase [13] and investigated the effect of contained water on expansion behavior.

In this study, they modified $\mathrm{TiO}_{2}$ powder with silane coupling agents so as to adher on the interface between the inner water droplets and the oil phase.

In this study, taking the formation of the stable $(\mathrm{W} / \mathrm{O}) / \mathrm{W}$ multiple emulsion and obtaining the higher water content into consideration, the microcapsules containing water were prepared with two kinds of microencapsulation methods, 
namely, the first was the microencapsulation of water with suspension polymerization and the second was the microencapsulation of water with suspension polymerization in parallel with interfacial polycondensation reaction. These preparation methods were easy operation compared with the stabilization of the (W/O)/W emulsion by the modified $\mathrm{TiO}_{2}$ powder or $\mathrm{SiC}$ powder [14].

The purposes of this study are to prepare the microcapsules containing water by forming the stable (W/O)/W multiple emulsion and to investigate the effect of the microencapsulated water on the expansion behaviour of microcapsules.

\section{Experimental}

\subsection{Materials}

Materials used to prepare the microcapsules containing water were as follows.

Styrene monomer (St: Wako Pure Chemical Co., Ltd., Tokyo, Japan) and Trimethyl propane triacrylate (TMPTA: Wako Pure Chemical Co., Ltd., Tokyo, Japan) were used as a polymerizable monomer and a crosslinking agent in the suspension polymerization process, respectively.

Toluene diisocyanate (TDI: Wako Pure Chemical Co., Ltd., Tokyo, Japan) and polyethylene glycol (PEG: Wako Pure Chemical Co., Ltd., Tokyo, Japan) were used as the oil soluble reactant and the water soluble reactant in the interfacial polycondensation process, respectively.

2,2'-Azobis 2,4-dimethylvaleronitrile (V-65: Wako Pure Chemical Co., Ltd., Tokyo, Japan) was used as the oil soluble initiator in the suspension polymerization process.

As the water soluble stabilizers, polyvinyl alcohol (PVA: Polym.degree 500 Wako Pure Chemical Co., Ltd., Tokyo, Japan) and hydroxyl propylmethyl cellulose (HPMC (60 SH-50): Shinetsu Chemical, Co., Ltd., Tokyo, Japan) were dissolved in the continuous water phase. As an oil soluble surfactant, polyglycerol polyricin oleate (POEM PR-100, Riken Vitamin Co., Ltd., Tokyo, Japan) was used.

As the oil soluble additives added to increase the water content, wax (Kanto Chemical Ltd., Tokyo, Japan) was added in the monomer phase in the suspension polymerization process. Also, as the hydrophilic additives, agarose and silicagel (Kanto Chemical Ltd., Tokyo, Japan) were added into the inner water phase.

\subsection{Preparation of Microcapsules}

The experimental apparatus was the same as one used in the previous work [15] [16].

Briefly, the reactor was the separable flask with the effective volume of $500 \mathrm{cc}$ and the four aluminum baffle plates, and set in the thermostatted water both. The impeller was the six bladed turbine with the diameter of $5.0 \mathrm{~cm}$.

Figure 1 shows the flow sheet for preparing the microcapsules. The suspension polymerization method was as follows, where all the abbreviations such as 


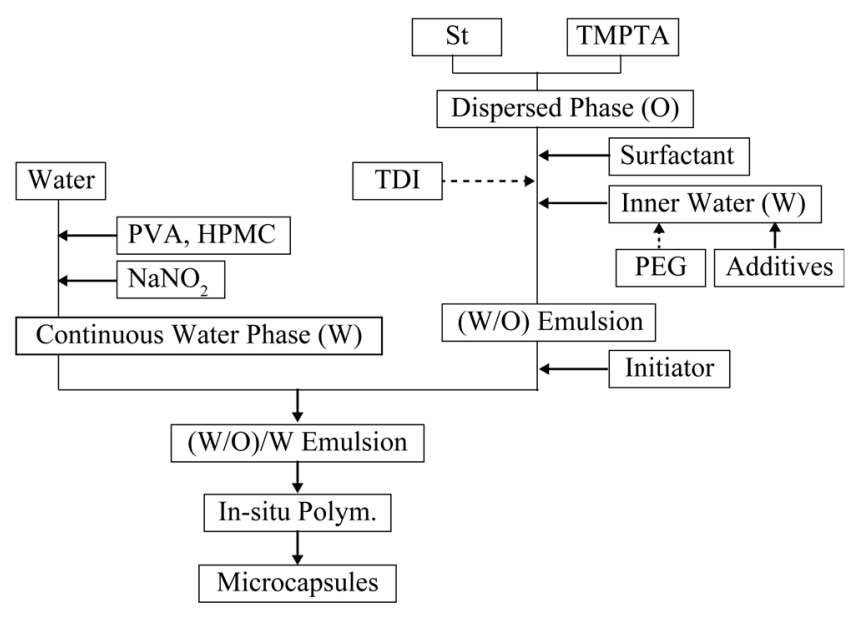

Figure 1. Flow sheet for preparing microcapsules.

PVA, HPMC, TDI, et al., are explained in the section of 2.1 materials.

St and TMPTA were mixed to form the dispersed oil phase $(\mathrm{O})$, where the oil soluble additives and the oil soluble surfactant were dissolved according to the experimental conditions.

The inner water (W) was added into the dispersed oil phase $(\mathrm{O})$ and homogenized with the homogenizer to form the (W/O) emulsion. Here, the water soluble additives were added into the inner water according to the experimental conditions beforehand. After this operation, the initiator of a given weight was added into the $(\mathrm{W} / \mathrm{O})$ emulsion.

Then, the $(\mathrm{W} / \mathrm{O})$ emulsion was added into the continuous water phase $(\mathrm{W})$ and stirred with the impeller to form the (W/O)/W emulsion. The water soluble stabilizer (PVA, HPMC) was dissolved in the continuous water phase beforehand. Also, sodium nitrite $\left(\mathrm{NaNO}_{2}\right)$ of a given weight was dissolved as an inhibitor in the continuous water phase.

After stirring the $(\mathrm{W} / \mathrm{O}) / \mathrm{W}$ emulsion during the constant time (10 min), suspension polymerization was performed for $7 \mathrm{~h}$ keeping reaction temperature at $70^{\circ} \mathrm{C}$.

Hereafter, the suspension polymerization method and the microcapsules prepared thus are called Process A and MCS, respectively.

Next, the suspension polymerization in parallel with interfacial polycondensaiton method was as follows.

TDI and PEG were added into the dispersed oil phase and the inner water phase, respectively. Then, $(\mathrm{W} / \mathrm{O})$ emulsion and the $(\mathrm{W} / \mathrm{O}) / \mathrm{W}$ emulsion were formed with the same method as one described above. Suspension polymerization in parallel with interfacial polymerization was performed for $7 \mathrm{~h}$ at $70^{\circ} \mathrm{C}$. Interfacial polycondensation was conducted to microencapsulate the inner water droplets and to increase the stability of the (W/O) emulsion and the water content.

Hereafter, the suspension polymerization in parallel with interfacial polycondensation method and the microcapsules prepared thus are called Process $\mathbf{B}$ and 
MCSI, respectively.

The experimental conditions were shown in Table 1.

\subsection{Characterization}

\subsubsection{Observation}

The microcapsules prepared with each preparation method were observed by optical microscope (OM: BH-2, OLYNPUS Co., Ltd., Tokyo, Japan) and scanning electron microscope (SEM, JST-5800, Nihon Denshi Co., Ltd., Tokyo, Japan).

The shape, section area and inner structure of microcapsules were evaluated from these results.

Also, the mean diameters of microcapsules were evaluated directly from the photographs taken by OM or SEM, and measured by particle size analyzer (SALD-3000, Shimazu Seisakusho Ind., Co., Ltd., Kyoto, Japan).

\subsubsection{Water Content}

The water content (R) was defined and calculated according to Equation (1).

$$
\mathrm{R}[\%]=\left(M_{w}-M_{o}\right) / M_{w} \times 100
$$

Table 1. Experimental conditions.

\begin{tabular}{|c|c|c|c|}
\hline \multicolumn{2}{|c|}{ Dispersed Oil Phase (O) } & \multicolumn{2}{|c|}{ Formation of $(\mathrm{W} / \mathrm{O}) / \mathrm{W}$ Emulsion } \\
\hline St & $33.0 \mathrm{~g}$ & Revolution Velocity & $\mathrm{Nr}_{2}=250 \mathrm{rpm}$ \\
\hline TMPTA & $\mathrm{C}_{\mathrm{T}}=0 \sim 2.5 \mathrm{~g}$ & Temperature & $\mathrm{T}_{2}=25^{\circ} \mathrm{C}$ \\
\hline POEM & $3.0 \mathrm{~g}$ & Stirring Time & $\mathrm{t}_{2}=10 \mathrm{~min}$ \\
\hline Wax & $0 \sim 5.0 \mathrm{~g}$ & & \\
\hline TDI & $0.12 \mathrm{~g}$ & & \\
\hline V-65 & $1.0 \mathrm{~g}$ & & \\
\hline \multicolumn{2}{|c|}{ Inner Water Phase (W) } & \multicolumn{2}{|c|}{ Suspension Polymerization } \\
\hline Water & $10 \mathrm{~g}$ & Revolution Velocity & $\mathrm{Nr}_{3}=250 \mathrm{rpm}$ \\
\hline PEG & $0.08 \mathrm{~g}$ & Temperature & $\mathrm{T}_{3}=60^{\circ} \mathrm{C}$ \\
\hline Agarose & $0.1 \mathrm{~g}$ & Stirring Time & $\mathrm{t}_{3}=7 \mathrm{~h}$ \\
\hline Silicagel & $0.1 \mathrm{~g}$ & & \\
\hline \multicolumn{2}{|c|}{ Continuous Phase (W) } & \multicolumn{2}{|c|}{ Interfacial Polymerization } \\
\hline Water & $280 \mathrm{~g}$ & Revolution Velocity & $\mathrm{Nr}_{4}=250 \mathrm{rpm}$ \\
\hline PVA & $0.33 \mathrm{wt} \%$ - water & Temperature & $\mathrm{T}_{4}=60^{\circ} \mathrm{C}$ \\
\hline HPMC & $0.17 \mathrm{wt} \%$ - water & Stirring Time & $\mathrm{t}_{4}=3 \mathrm{~h}$ \\
\hline \multicolumn{4}{|c|}{ Formation of $(\mathrm{W} / \mathrm{O})$ Emulsion } \\
\hline Revolution Velocity & $\mathrm{Nr}_{1}=12000 \mathrm{rpm}$ & \multicolumn{2}{|c|}{ Expansion } \\
\hline Temperature & $\mathrm{T}_{1}=25^{\circ} \mathrm{C}$ & Temperature & $\mathrm{T}_{5}=110 \sim 150^{\circ} \mathrm{C}$ \\
\hline Stirring Time & $\mathrm{t}_{1}=10 \mathrm{~min}$ & Time & $\mathrm{T}_{5}=30 \mathrm{~min}$ \\
\hline
\end{tabular}


where $\mathrm{M}_{\mathrm{w}}$ and $\mathrm{M}_{\mathrm{o}}$ are the weights of microcapsules after being kept at $\mathrm{T}=44^{\circ} \mathrm{C}$ for 1 week and at temperature higher than $\mathrm{T}=110^{\circ} \mathrm{C}$ for 1 week, respectively.

The reason why the water content was calculated basing on the microcapsules after being kept at $\mathrm{T}=44^{\circ} \mathrm{C}$ for 1 week and at $\mathrm{T}=110^{\circ} \mathrm{C}$ for 1 week was as follows.

A part of water microencapsulated must evaporate as vapor at room temperature during storage. The water vaporized at room temperature may not contribute to expanding the microcapsules [17] [18].

Accordingly, the microcapsules were dried at $\mathrm{T}=44^{\circ} \mathrm{C}$ for 1 week to perfectly remove water which did not contribute to expanding the microcapsules.

Water contained even after being kept at the conditions described above must contribute to expanding the microcapsules and act as a blowing agent.

\subsubsection{Measurement of Expansion Ratio}

The expansion ratio (E) of microcapsules was measured as follows.

Namely, the microcapsules of a given weight were added into ethylene glycol at each temperature higher than $110^{\circ} \mathrm{C}$ and kept for $60 \mathrm{~min}$.

After this operation, the diameters of microcapsules were measured with particle size analyzer and the expansion ratio was defined and calculated according to Equation (2)

$$
\mathrm{E}[-]=\left(\mathrm{d}_{\mathrm{PE}} / \mathrm{d}_{\mathrm{p}}\right)
$$

where $d_{P E}$ and $d_{p}$ are the mean diameters after and before adding into ethylene glycol kept at designated temperature.

\section{Results and Discussion}

\subsection{Effect of Additives on Water Content and Expansion Ratio}

\section{(1) Effect of Crosslinking Agent}

Figure 2 shows the dependences of the water content $(\mathrm{R})$ and the expansion ratio $(E)$ on the crosslinking agent concentration $\left(C_{T}\right)$ for Process $A$.

With increasing the crosslinking agent concentration, the water content $(\mathrm{R})$ slightly increased from $\mathrm{R}=5.9 \%\left(\mathrm{C}_{\mathrm{T}}=0\right)$ to $\mathrm{R}=8.2\left(\mathrm{C}_{\mathrm{T}}=4 \%\right)$ and became almost constant $(\mathrm{R}=8.2 \%)$.

On the other hand, with increasing the crosslinking agent concentration, the expansion ratio increased from $\mathrm{E}=1.01\left(\mathrm{C}_{\mathrm{T}}=0\right)$ to $\mathrm{E}=2.3\left(\mathrm{C}_{\mathrm{T}}=4.0 \%\right)$ and then, decreased.

Figure 3 shows the SEM photographs of the whole and inner structure of microcapsules before and after expansion, where the microcapsules were prepared by changing the crosslinking agent concentration. From these photographs, it is found that water could be microencapsulated well and the interior space at $\mathrm{C}_{\mathrm{T}}=$ $4.0 \mathrm{wt} \%$ became lager than $\mathrm{C}_{\mathrm{T}}=7.0 \mathrm{wt} \%$.

Comparing the inner structure at $\mathrm{C}_{\mathrm{T}}=4.0 \mathrm{wt} \%$ with that at $\mathrm{C}_{\mathrm{T}}=7.0 \mathrm{wt} \%$, the expansion ratio for the former is found to be larger in spite of smaller difference in the water content. 

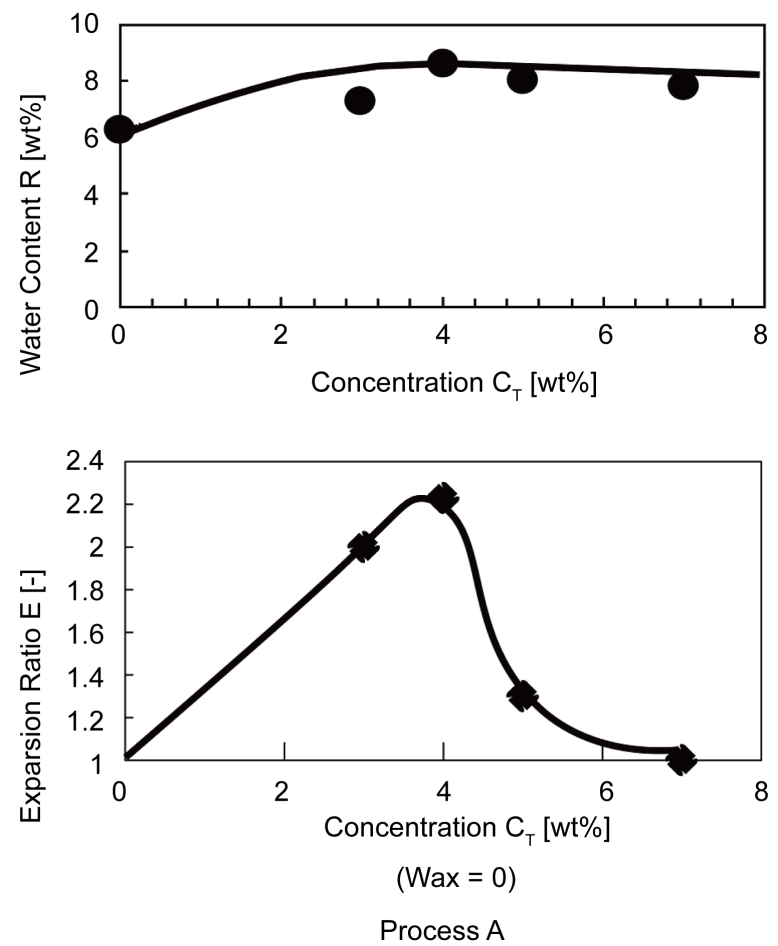

Figure 2. Effect of crosslinking agent concentration.

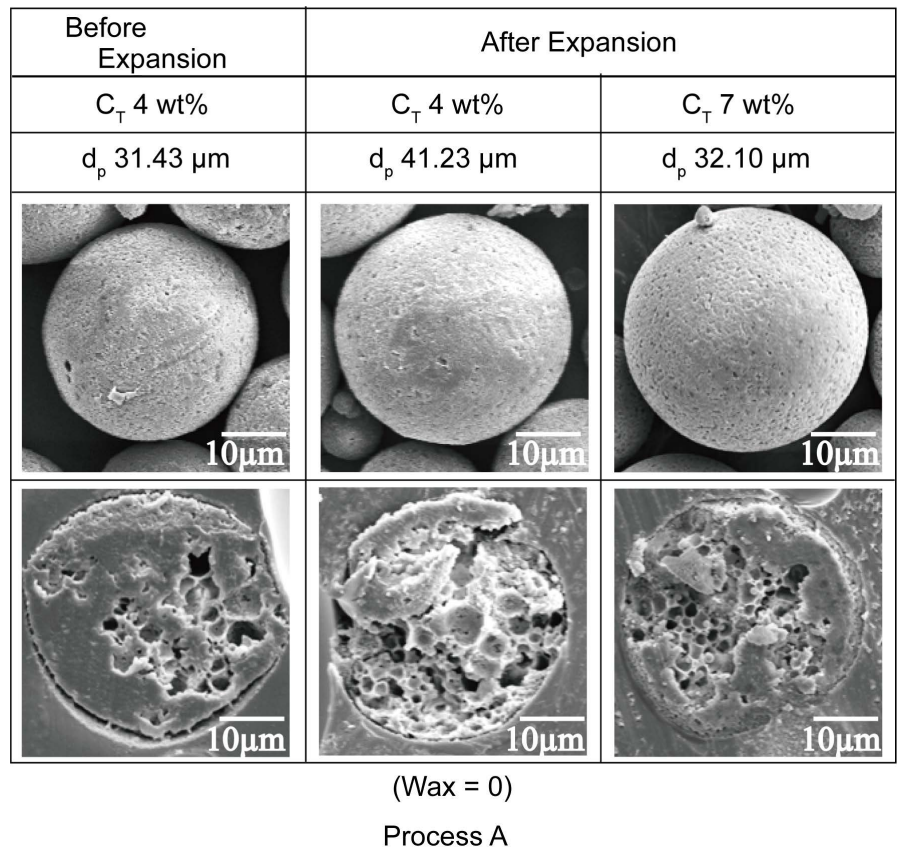

Figure 3. SEM photographs of microcapsules before and after expansion.

This result may be due to the fact that the microcapsules prepared at $\mathrm{C}_{\mathrm{T}}=7.0$ wt $\%$ could not be expanded owing to the higher crosslinking density.

\section{(2) Effect of Wax}

In order to prevent the water evaporation and to increase the water content, stronger hydrophobic wax was added in the monomer phase and the effect on 
the water content and the expansion ratio was investigated.

Figure 4 shows the dependences of the water content $(\mathrm{R})$ and the expansion ratio (E) on the added amount of wax for Process A.

With increasing the added amount of wax, the water content gradually increased, while the expansion ratio increased, became maximum $(\mathrm{E}=1.55)$ at $\mathrm{W}$ $=3.0$ and then, decreased.

Figure 5 shows the SEM photographs of the inner structures of expanded microcapsules prepared changing the added amount of wax.

From these photographs, it is clearly found that the microcapsules prepared adding wax was largely expanded.

This result may be due to the fact that by adding wax, the water content could be increased and evaporation of inner water during the expansion process could be prevented with hydrophobicity of wax.

The decrease in the expansion ratio at the added amount lager than $3.0 \mathrm{~g}$ may be due to the fact that more tiny cracks were easy to be formed at crystallization on the region between wax and the matrix polymer, as a result, the inner water may be easy to evaporate, though these cracks could not be clearly observed.

\section{(3) Effect of Silicagel and Agarose}

It is important to increase the water content in order to accomplish the larger expansion ratio. For this, it was tried to add the water absorbable additives, Agarose and shilicagel, for Process A.

Figure 6 shows the dependences of the water content and the expansion ratio on the addition of silicagel and Agarose for Process A.

The water content and the expansion ratio could be increased by adding silicagel and Agarose from $\mathrm{R}=5.2 \mathrm{wt} \%$ (without) to $\mathrm{R}=7.8 \mathrm{wt} \%$ (silicagel) and $\mathrm{R}=$
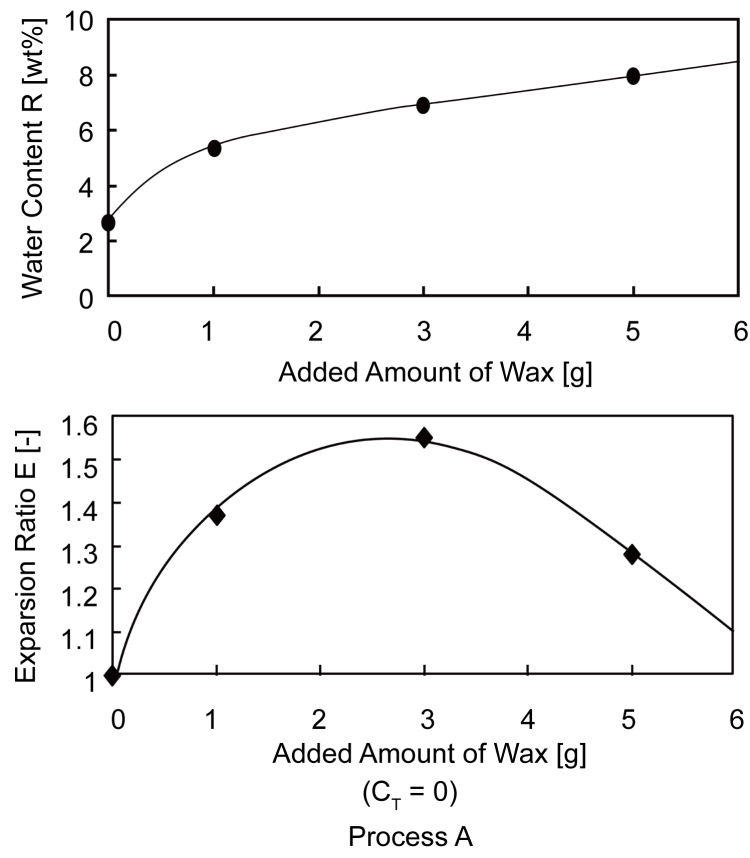

Figure 4. Effect of wax addition. 


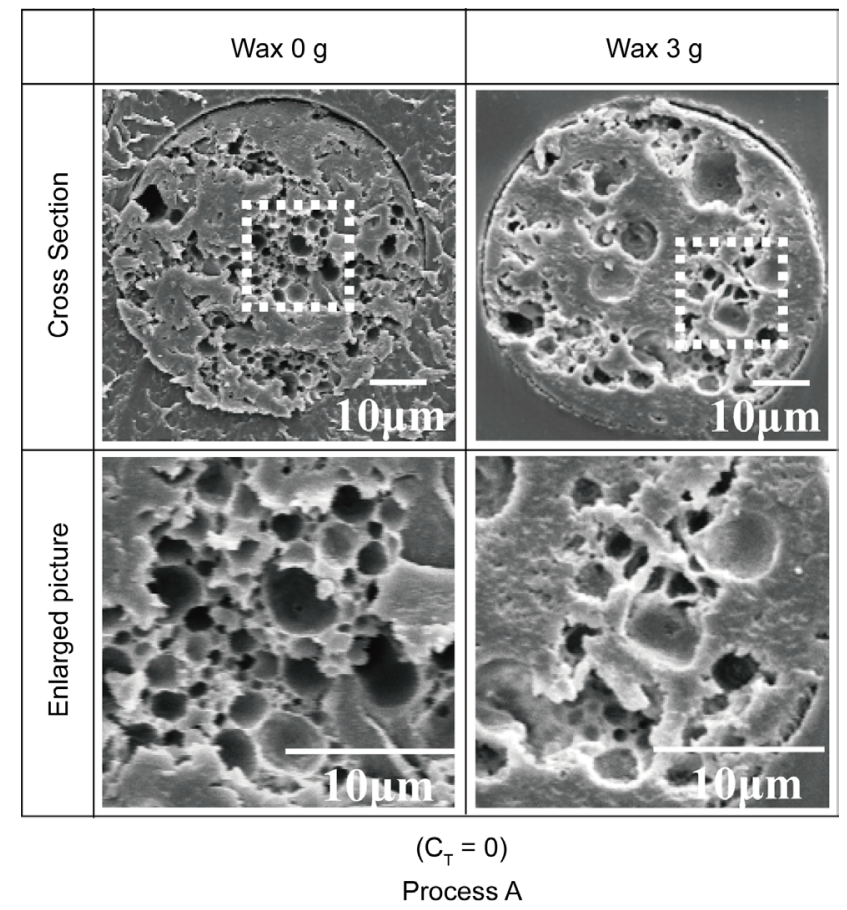

Figure 5. Effect of added amount of wax.

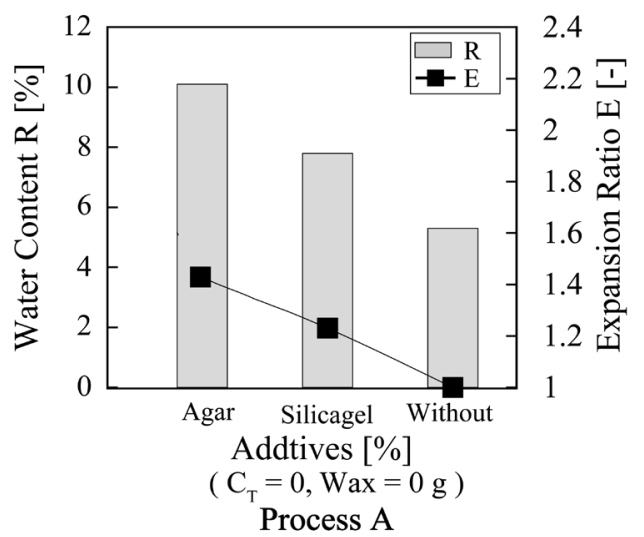

Figure 6. Effect of agar and silicagel.

$10.5 \mathrm{wt} \%$ (Agarose) and from $\mathrm{E}=1.01$ (without) to $\mathrm{E}=1.25 \%$ (silicagel) and $\mathrm{E}=$ $1.42 \%$ (Agarose), respectively.

Figure 7 shows the SEM photographs of the whole and inner structure of microcapsules prepared adding silicagel and Agarose.

From these photographs, it could not be clearly recognized the difference due to the kinds of additives.

However, the opening areas for the microcapsules with Agarose are larger than those for microcapsules with silicagel.

\subsection{Effect of Microencapsulation Method on Water Content and Expansion Ratio}

Figure 8 shows the dependences of the water content $(\mathrm{R})$ and the expansion ra- 


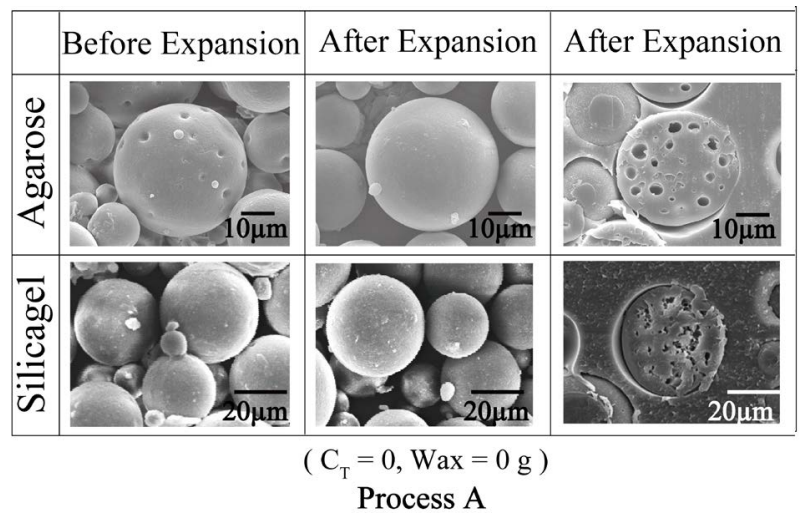

Figure 7. SEM photographs of microcapsules before and after expansion.

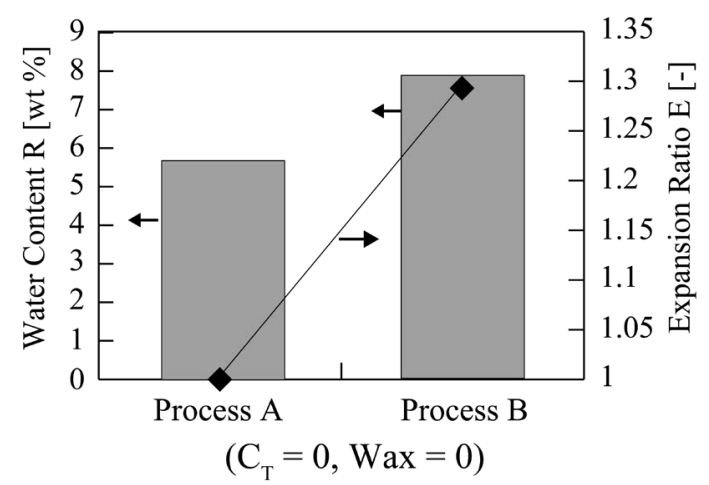

Figure 8. Effect of preparation method on water content and expansion ratio.

tio (E) on the microencapsulation method.

In the case of Process $\mathrm{A}$, the water content $(\mathrm{R})$ and the expansion ratio (E) were $\mathrm{R}=5.9 \mathrm{wt} \%$ and $\mathrm{E}=1.01$, respectively. On the other hand, in the case of Process $\mathrm{B}$, the water content $(\mathrm{R})$ and the expansion ratio (E) were $\mathrm{R}=\mathrm{ca} .8 \mathrm{wt} \%$ and $\mathrm{E}=1.3$, respectively.

For the polymer beads to expand due to the contained water, it is necessary that the contained water must expand in the polymer matrix without escaping through the polymer matrix.

Accordingly, the reason why the expansion ratio became $\mathrm{E}=1.01 \%$ for Process A may be due to the fact that the water rapidly escaped through the polymer matrix in addition to smaller water content [19] [20].

Contrary to this, the reason why the water content and the expansion ratio became $\mathrm{R}=8.0 \mathrm{wt} \%$ and $\mathrm{E}=\mathrm{ca} .1 .3 \%$ for Process $\mathrm{B}$ may be due to the fact that the $(\mathrm{W} / \mathrm{O})$ emulsion could be stabilized and water could be prevented from escaping with the polyurethane shell formed on the surface of the inner water droplets.

\subsection{Effect of Expansion Temperature on Expansion Ratio}

As expansion temperature affects the expansion behaviour of microcapsules, 


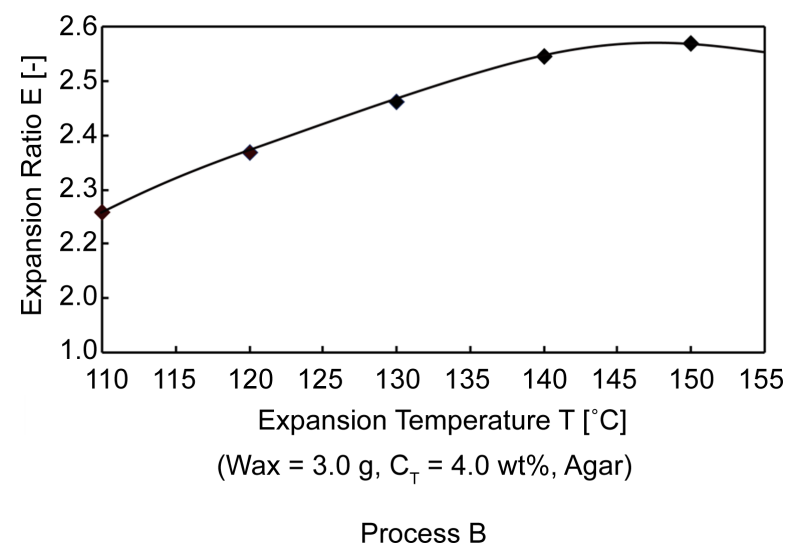

Figure 9. Effect of expansion temperature on expansion ratio.

namely, melting of polymer matrix and expansion of contained water, the effect of expansion temperature on expansion behavior was investigated, where the microcapsules were prepared under the conditions such as $\mathrm{C}_{\mathrm{T}}=4.0 \mathrm{wt} \%, 3.0 \mathrm{~g}$ of wax, addition of Agarose.

Figure 9 shows the dependence of expansion ratio on expansion temperature. Expansion ratio increased from $\mathrm{E}=2.25$ at $\mathrm{T}=110^{\circ} \mathrm{C}$ to $\mathrm{E}=2.58$ at $\mathrm{T}=150^{\circ} \mathrm{C}$ with expansion temperature for Process B.

Higher expansion temperature must increase the expansion volume of water contained in the polymer matrix and promote melting of matrix.

Accordingly, the higher the expansion temperature, the larger the expansion ratio.

\section{Conclusions}

The microcapsules containing water were prepared with the suspension polymerization method and the suspension polymerization in parallel with interfacial polycondensation method using the $(\mathrm{W} / \mathrm{O}) / \mathrm{W}$ emulsion. The effect of the experimental conditions on the water content and the expansion ratio was investigated and the following results were obtained.

The water content and the expansion ratio could be increased by adding the crosslinking agent, wax and hydrophilic additives.

The water content could be increased by forming the polyurethane shell on the surface of the inner water droplets; as a result, the expansion ratio could be increased.

However, there were the optimum concentration of crosslinking agent and the added amount of wax required to increase the expansion ratio.

In the near future, the effect of the physical properties of matrix polymer of microcapsules such as modules of elasticity and melting point should be discussed.

\section{References}

[1] Kondo, T. (1967) Saishin Maikurokapuseruka Gijutsu [Microencapsulation Tech- 
nique] (in Japanese). ETS, Tokyo.

[2] Tanaka, M. (2008) Key Point of Preparation of Nano/Microcapsules. Techno System Publishing Co. Ltd., Tokyo.

[3] Wang, J., Shi, A., Agyei, D. and Wang, Q. (2017) Formulation of Water-in-Oil-in-Water (W/O/W) Emulsions Containing Trans-Resveratrol, RSC Advances, 35917-35927. https://doi.org/10.1039/C7RA05945K

[4] Sekine, T., Yoshinori, K., Matsuzaki, F., Yanaki, T. and Yamaguchi, M. (1999) A Novel Method for Preparing Oil-in-Water-Oil Type Multiple Emulsions Using Organophilic Montmorilloite Clay Mineral. Journal of Surfactants and Detergents, 2, 309-315. https://doi.org/10.1007/s11743-999-0082-7

[5] Pistel, K.F. and Kissel, T. (2000) Effects of Salf Addition on the Microencapsulation of Proteins Using W/O/W Double Emulsion Technique. Journal of Microencapsulation, 17, 467-483.

[6] Kim, J.H., Cho, Y.H., Bae, E.K., Shig, T.S., Shoi, S.W., Choi K.H. and Jiyong, P. (2005) Development of W/O/W Multiple Emulsion Formulaton Containing Burkholderia gladioli. Journal of Microbiolosy and Biotechnology, 15, 29-34.

[7] Tanaka, M. and O'shima, E. (1982) Effect of Viscosity of Continuous Phase on Stability of Droplets in Suspension Polymerization of Styrene. Kagaku Kogaku Ronbunshu, 8, 734-738. https://doi.org/10.1252/kakoronbunshu.8.734

[8] Tanaka, M., Hashimoto, K. and Nakada, K. (1979) Effect of Solid Powders on Stability of Emulsion. Oil Chemistry, 28, 491-496.

https://doi.org/10.5650/jos1956.28.491

[9] Kiyoyama, S., Ueno, H., Shiomori, K., Kawano, Y., and Hatate, Y. (2001) Preparatin of Cross-Linked Microcapsules Entapping Inorganic Salt by In-Situ Polymerization in (W/O/W) Emulsion System. Journal of Chemical Engineering of Japan, 34, 36-42. https://doi.org/10.1252/jcej.34.36

[10] Kawano, Y., Shiomori, K., Kiyoyama, S., Takeshita, K. and Hatate, Y. (2001) Cheracteristics of Biodegradable Microcapsules by Solvent Evaporation in (W/O/W) Emulsion System. Journal of Chemical Engineering Japan, 34, 1182-1186. https://doi.org/10.1252/jcej.34.1182

[11] O'shima, E. and Tanaka, M. (1982) Effect of Solid Powders on Stability of Suspension Polymerization of Styrene. Kagaku Kogaku Ronbunshu, 8, 188-193. https://doi.org/10.1252/kakoronbunshu.8.188

[12] Tanaka, M. and Hayashi, K. (1990) Preparation of Polymer Particles Covered with Ferrite Powder by Suspension Polymerization: Effect of Wettability of Powder on Composite Particle Size Distribution. Journal of Material Science, 25, 987-991. https://doi.org/10.1007/BF03372191

[13] Nakamura, D., Yokoyama, H., Taguchi, Y. and Tanaka, M. (2014) Preparation of Microcapsules Containing Water Droplets Stabilized with Solid Powder and Application to Blowing Agent. Materials Sciences and Applications, 5, 20-26.

[14] Tanaka, M., Hosogai, K., Yuda, T., Kimura, I. and Saito, N. (1992) Preparation of Composite Particles Composed of Polystyrene and Carbon Silicide by Suspension Polymerization. Journal of the Japan Society of Colour Material, 65, 484-491. https://doi.org/10.4011/shikizai1937.65.484

[15] O'shima, E. and Tanaka, M. (1982) Coalescence and Breakup of Droplets in Suspension Polymerization of Styrene. Kagaku Kogaku Ronbunshu, 8, 86-90. https://doi.org/10.1252/kakoronbunshu.8.86

[16] Tanaka, M. and Hayashi, K. (1989) Preparation of Polystyrene Particles Coated with 
Ferrite Powder by Suspension Polymerizaion. Kagaku Kougaku Ronbunshu, 15, 1144-1152. https://doi.org/10.1252/kakoronbunshu.15.1144

[17] Pallay, J. and Berghmans, H. (2002) Water-Blown Expandable Polystyrene. Improvement of the Compatibility of the Water Carrier with the Polystyrene Matrix by in Situ Grafting Part 1, 2. Mechanism of Free Radical Grafting. Cellular Polymers, 21, 1-18.

[18] Pallay, J. and Berghmans, H. (2002) Water-Blown Expandable Polystyrene. Improvement of the Compatibility of the Water Carrier with the Polystyrene Matrix by in Situ Grafting Part 2. Influence of Compatibilization on the Foam Quality. Cellular Polymers, 21, 19-33.

[19] Pallay, J., Kelemen, P., Berghmans, H. and Dommelen, D.V. (2000) Expansion of Polystyrene using Water as the Blowing Agent. Macromolecular Materials and Engineering, 275, 18-25.

https://doi.org/10.1002/(SICI)1439-2054(20000201)275:1<18::AID-MAME18>3.0.C $\underline{\mathrm{O} ; 2-3}$

[20] Pallay, J., Pallayova, S. and Berghmans, H. (2007) Expansion of Polystyrene using Water as the Blowing Agent. Journal of Cellular Pastics, 43, 371-383.

https://doi.org/10.1177/0021955X07079208 